\title{
CYTED-BT: An international biotechnology network that works
}

\author{
Harvey Bialy
}

Too often, international programs for cooperation in biotechnology, particularly those involving "developing" countries, begin with the best intentions, but over time, sadly, produce very little in the form of tangible accomplishment. Thus, it is both refreshing and encouraging to find notable counterexamples. One such is the biotechnology subprogram of CYTED (an acronym for the Program of Science and Technology for Development) that was inaugurated in 1982 by the Spanish government, together with Portugal and all 19 Latin American countries, to establish a network of scientific and technologic cooperation within this very large region.

The overall project comprises 16 different subprograms that cover areas as diverse as microelectronics, robotics, aquaculture, new materials, low-cost housing, catalysis, food preservation, energy, and most recently, biotechnology. Perhaps the most attractive feature of the CYTED organization is its simplicity. Each of the subprograms, which is directed by a single coordinator chosen by the general assembly of participating countries, has an enviable autonomy. In the case of the biotechnology component (CYTEDBT) this has allowed it to be extremely flexible and innovative in responding to a changing scientific and commercial climate.

CYTED-BT, established in 1987, was charged with using the most modern tools of genetic engineering to develop new products that fulfill unmet needs in the health and food sectors. Its first goal was to produce a rapid, low-cost, and highly accurate diagnostic for Chagas' disease, a parasitic ailment that affects about 18 million people and puts an additional 100 million inhabitants of South America at risk of infection. In most countries in the central portion of the continent, for instance, it is estimated that the population at risk is close to $50 \%$ with a prevalence of human infection of the order of $10 \%$.

To develop the Chagas' test, Rafael Rangel-Aldao - the project leader, and (since 1994) the subprogram's international coordinator-put together a group of colleagues from Argentina, Brazil, Spain, and Venezuela who had independently cloned several antigens of the causative agent of Chagas' disease, the protozoan Trypanosoma cruzi. (RangelAldao also directs the biotechnology unit of Empresas Polar, and is a professor at Simon
Bolivar University, Caracas, Venezuela.)

The group met for the first time in 1990 at the laboratory of Mariano Levin from the Research Institute of Genetic Engineering and Molecular Biology (INGEBI) in Buenos Aires to select those recombinant antigens that gave the best sensitivity and specificity when tested against a panel of coded sera. The member laboratories of the network had previously collected such samples from infected and noninfected patients in most Latin American countries, and had sent the sera to be characterized and coded at the laboratory of Mario Camargo of the Institute of Tropical Medicine of the University of São Paulo.

As a result of the 1990 workshop, and with the help of software developed by Wim Degrave from the Oswaldo Cruz Foundation in Rio de Janeiro, Brazil, the CYTED investigators selected recombinant antigens from the laboratories of Levin and Jose Franco da Silveira of the São Paulo Medical School in Brazil. These molecules were to be configured for an ELISA format that was to be further enriched with antigens from the laboratories of Antonio González of the Institute López Neyra in Granada, Spain, and from Bianca Zingales of the University of São Paulo.

The pilot-scale production of the recombinant antigens was subsequently performed at the laboratory of Mariano Levin, and their incorporation into an ELISA test was done in São Paulo under the direction of Mario Camargo and Eufrosina Umezawa and the general coordination of Jose Franco da Silveira. In the following years and after extensive testing, the group developed a highly sensitive and specific ELISA kit that could be used for screening Chagas' disease in blood banks. At that benchmark juncture, an American biotechnology company, ChemBio Diagnostic Systems (CDS, Medford, NY) offered to cooperate in transforming the ELISA format to a simpler, low-cost, and rapid immunochromatographic assay that could detect blood or serum antibodies to T. cruzi within minutes.

In late 1996 an agreement was signed between CYTED-BT and CDS, and by the middle of 1997 , kits that resemble over-thecounter home pregnancy tests were being evaluated in key laboratories and Chagas' reference centers throughout Latin America.
Called Chagas Stat-Pak, the kit is also currently being evaluated by a laboratory at the US Centers for Disease Control and Prevention (Atlanta, GA). In anticipation of bringing the test to market by the end of this year, CYTED-BT incorporated a company in New York, BIOCYTED Inc., as a vehicle to handle this and future collaborations with other biotechnology companies that are interested in entering into the Latin American health markets. The total price tag for this project was an impressively modest $\$ 200,000$.

In another related activity, CYTED-BT became involved in the genome of $T$. cruzi by establishing a collaborating network of scientists that allowed it to orchestrate additional funding (genomics is considerably more expensive than diagnostics) for their laboratories from local sources, as well as international agencies such as the World Health Organization (WHO; Geneva). (In collaboration with WHO, CYTED-BT launched, in 1994, the T. cruzi genome project.) Because of its role in promoting and facilitating the capability to map and sequence DNA and to produce and exchange genomic information with colleagues around the world, the network played a role in the launch by the Brazilian government of its own genome project to study a bacteria that causes severe damage to one of their principal export products, oranges (see "ONSA, the São Paulo Virtual Genomics Institute," p. 795).

More directly, CYTED-BT has expanded into food production by creating a multinational and interdisciplinary team to cooperate in the development of genetic constructions for the simultaneous introduction of viral and other pathogen resistances into Latin American potato varieties. The team is coordinated by Alejandro Mentaberry from INGEBI, and consists of plant molecular biologists and traditional plant breeders from Argentina, Brazil, Chile, Cuba, Peru, Uruguay, Spain, France, Germany, and the United States.

From its inception, CYTED-BT has been built on the principle of choosing welldefined scientific and technical goals and allowing the scientists most directly concerned the fullest possible freedom to accomplish them. Its adherence to this principle might be the key reason that the CYTED-BT network has worked so well. 